\title{
Influences for Gender Disparity in Academic Neuroradiology
}

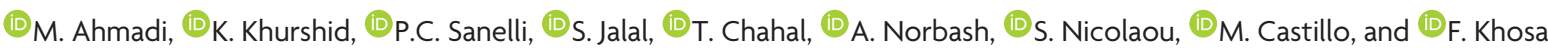

\begin{abstract}
BACKGROUND AND PURPOSE: There has been extensive interest in promoting gender equality within radiology, a predominately male field. In this study, our aim was to quantify gender representation in neuroradiology faculty rankings and determine any related factors that may contribute to any such disparity.
\end{abstract}

MATERIALS AND METHODS: We evaluated the academic and administrative faculty members of neuroradiology divisions for all on-line listed programs in the US and Canada. After excluding programs that did not fulfill our selection criteria, we generated a short list of 85 US and 8 Canadian programs. We found 465 faculty members who met the inclusion criteria for our study. We used Elsevier's SCOPUS for gathering the data pertaining to the publications, $\mathrm{H}$-index, citations, and tenure of the productivity of each faculty member.

RESULTS: Gender disparity was insignificant when analyzing academic ranks. There are more men working in neuroimaging relative to women $\left(\chi^{2}=0.46 ; P=.79\right)$. However, gender disparity was highly significant for leadership positions in neuroradiology $\left(\chi^{2}=6.76 ; P=\right.$ .009). The median $\mathrm{H}$-index was higher among male faculty members (17.5) versus female faculty members (9). Female faculty members have odds of 0.84 compared with male faculty members of having a higher $\mathrm{H}$-index, adjusting for publications, citations, academic ranks, leadership ranks, and interaction between gender and publications and gender and citations (9).

CONCLUSIONS: Neuroradiology faculty members follow the same male predominance seen in many other specialties of medicine. In this study, issues such as mentoring, role models, opportunities to engage in leadership/research activities, funding opportunities, and mindfulness regarding research productivity are explored.

G ender disparity among medical students, residents, physicians, and faculty members is widespread, and several reports show an underrepresentation of women in academic medicine. ${ }^{1-6}$ It is interesting to note that in North America (US and Canada), female physicians have been shown to be equally likely as men to pursue a career in academic medicine. ${ }^{5}$ Despite the similar amount of prospective interest in academics, the proportion of women who successfully advance to the rank of professor is significantly lower. ${ }^{7,8}$ Women who occupy faculty positions are also more likely to leave academics for commu-

Received June 18, 2017; accepted after revision August 8.

From the Department of Emergency \& Trauma Radiology (M.A., K.K., S.J., S.N., F.K.), Vancouver General Hospital, Vancouver, British Columbia, Canada; Faculty of Med icine (T.C.), University of British Columbia, Vancouver, British Columbia, Canada;

Department of Radiology (P.C.S.), Northwell Health, Manhasset, New York; Department of Radiology (A.N.) University of California, San Diego, San Diego, California; and Department of Radiology (M.C.), University of North Carolina School of Medicine, Chapel Hill, North Carolina.

Please address correspondence to Faisal Khosa, MD, MBA, FFRRCSI, FRCPC, DABR, 3350-950 W 10th Avenue, Vancouver, BC, Canada V5Z 1M9; e-mail:

fkhosa@gmail.com

http://dx.doi.org/10.3174/ajnr.A5443 nity or hospital practices. ${ }^{9}$ This has been explained in part by a lack of adequate mentorship and the inability of women to be promoted at the same pace and on the same timeline as men. These factors contribute to the relative lack of female leaders in academic medicine.

Although there is gender parity for medical students and residents in the North America, when analyzing faculty members of medical institutions, female physicians only constitute $38 \%$ of faculty rosters. ${ }^{1,3}$ When examining senior academic administration, the gender disparity increases even further. In the US, women account for only $21 \%$ of full professors, $16 \%$ of medical school deans, and $15 \%$ of department chairs. ${ }^{1,3}$ The only academic rank in which women outnumber men in the US is the clinical instructor level. ${ }^{1}$

This is a concern because increased diversity allows for a more creative, productive, egalitarian, and innovative environment. A lack of gender parity within faculty rankings may specifically also adversely affect initiatives, collaborations, and research efforts where women's health is concerned. The described gender disparity also leads to a lack of female faculty members serving as mentors and role models. Medical students and those interested in 
pursuing medicine look to mentors for encouragement and inspiration. ${ }^{10-12}$ The lack of strong corrective actions regarding gender disparities within academic medicine over the past decade suggests the need for active intervention. ${ }^{1,3,10,11}$ An improved understanding of gender disparities in academic medicine would allow solutions to be formulated and implemented.

Previous research in anesthesia, gastroenterology, ophthalmology, otolaryngology, plastic surgery, and general surgery highlight gender disparities favoring men in relation to factors such as research productivity, income, leadership, and faculty promotion. ${ }^{13-19}$ Not surprisingly, previous studies have also shown a similar male predominance in radiology. ${ }^{20-22}$

Radiology has men overrepresented in residency programs, academic departments, and private practice groups. ${ }^{21}$ Prior reports show that in the US, women occupy $27 \%$ of the radiology residency positions. ${ }^{23}$ When investigating contributory reasons, surveys of medical students have shown a lack of exposure early in their training, a lack of role models, and the apparent lack of patient contact as major deterrents for women considering radiology as a career choice. ${ }^{24-26}$

Prior reports have shown that women across the US are underrepresented in radiology senior faculty positions. ${ }^{20,22}$ A study of female representation in radiology subspecialties such as neuroradiology has not been published in the literature. Our aim was to quantify the gender imbalance of neuroradiology faculty rankings and related or explanatory factors that may contribute to such a disparity. Our hope is our findings will help initiate additional research, and ultimately interventions, in both neuroradiology and the larger academic medical community.

\section{MATERIALS AND METHODS}

We tabulated the gender of academic and administrative faculty members in the neuroradiology divisions of all the programs across the US and Canada. First, we created a list of all diagnostic radiology programs in North America (Canada and US) by using the Web site of the Fellowship \& Residency Electronic Interactive Database, or FREIDA, which provides a list of 227 Accreditation Council for Graduate Medical Education-accredited diagnostic radiology programs of the American Medical Association. For the diagnostic radiology programs in Canada, we referred to the Canadian Resident Matching Service Web site, which provided a total of 16 programs. Using these Web sites, we compiled the list of diagnostic radiology programs that included their faculty rosters on their individual Web sites. We excluded programs that did not include faculty rosters and those that had rosters but did not provide any information regarding administrative or faculty rank. We then filtered the remaining programs to specifically identify neuroradiology programs. After applying these selection criteria, we evaluated 85 US and 8 Canadian programs. Data collection started in July 2016 and included reviewing selected programs' Web sites for their faculty rosters and individual faculty. Inclusion criteria were full-time faculty members with the academic rank of professor, associate professor, or assistant professor with MD degrees and a listing on the affiliated university Web site. Faculty with departmental leadership roles such as chair, vice chair, program director, and associate and assistant program directors were included. Faculty not having stated academic ranks were ex- cluded. Exclusion criteria were also applied to adjunct, emeritus, and retired faculty as well as faculty who did not have an MD degree or whose gender could not be ascertained. We used Elsevier's SCOPUS to determine the individual faculty member's publications, $\mathrm{H}$-index, citations, and productivity. SCOPUS was chosen because it is a robust and reliable tool for measuring the $\mathrm{H}$-index compared with Google Scholar and Web of Science.

\section{RESULTS}

We found 465 faculty members who met the inclusion criteria of our study. Among them, 76.9\% (358/465) were men and 23.01\% (107/465) were women. Most of them (87.3\% [406/465]) were from the US, and $12.69 \%$ (59/465) were from Canada (Table 1). Faculty academic ranks were available for 447 . Among them, $50.34 \%(225 / 447)$ were assistant professors, $27.74 \%$ (124/447) were associate professors, and $21.92 \%$ (98/447) were professors. Of the assistant professors, $75.11 \%$ (169/255) were men, whereas $24.89 \%(56 / 255)$ were women. Among associate professors, $76.61 \%$ (95/124) were men, whereas only $23.39 \%$ (29/124) were women. Last, among the professors, $78.57 \%$ (77/98) were men; however, $21.43 \%$ (21/98) were women. Of the 72 faculty serving in leadership positions, $84.7 \%$ (61/72) were men, and $15.28 \%$ $(11 / 72)$ were women. Of those in the higher leadership ranks, $91.8 \%$ (56/61) were men, and only $8.2 \%$ (5/61) were women. In lower leadership ranks (eg, co-chair, deputy director), 63.6\% were men (7/11), and 36.36\% were women (4/11).

Data for citations, publication, and $\mathrm{H}$-index did not follow a conventional or balanced distribution. For that reason, medians, ranges, and nonparametric tests were carried out. To calculate regression, all variables were first log-transformed.

In the bivariate analysis, the $\chi^{2}$ test was used to evaluate the association of gender with academic and leadership rank.

There was a higher number of men (358 [76.9\%]) among the neuroradiology faculty compared with women (107; [23.01\%]). When considering gender incidence against leadership rank, the gender discrepancy was evidenced as highly significant $\left(\chi^{2}=\right.$ $6.76 ; P=.009$ ), with $87.5 \%$ of leadership ranks occupied by men compared with $12.5 \%$ of leadership ranks occupied with women. The median of time spent in academia among the male faculty was 20 years and was 17 years among the female faculty.

$\mathrm{H}$-index was noted for 360 faculty members. After testing for association of gender with $\mathrm{H}$-index using the Wilcoxon rank sum test, we found an insignificant difference (test statistics $=0.46$; $P=.794$ ) when assessing the 2 genders. Upon applying the Kruskall-Wallis test, there was a significant difference between academic rank $\mathrm{H}$-index (Fig 1) across all academic ranks $\left(\chi^{2}=\right.$ 113.32; $P<.001$ ), with a median male $\mathrm{H}$-index of 17.5 and a median female $\mathrm{H}$-index of 9.

Data were tested for normality. Log-transformation was performed considering the continuous variables of $\mathrm{H}$-index, citations, and the number of publications, which were initially skewed in distribution. At the univariate level, simple linear regression was applied. Each variable was regressed independently considering $\mathrm{H}$-index, the assumptions were assessed, and their significance was reported. Gender relationships were our primary consideration of interest. Variables that both were investigated and were significant on univariate regression included gender, 
Table 1: Description of baseline characteristics for neuroimaging faculty in North America

\begin{tabular}{|c|c|c|c|}
\hline Variables & Men & Women & $\begin{array}{c}\text { Total Available } \\
\text { Numbers }\end{array}$ \\
\hline Total population, no. (\%) & $358(76.9)$ & $107(23.01)$ & $465(100)$ \\
\hline \multicolumn{4}{|l|}{ Academic ranks, no. (\%) } \\
\hline Assistant professors & $169(75.11)$ & $56(24.89)$ & $225(100)$ \\
\hline Associate professors & $95(76.61)$ & $29(23.39)$ & $124(100)$ \\
\hline Professors & $77(78.57)$ & $21(21.43)$ & $98(100)$ \\
\hline \multicolumn{4}{|l|}{ Leadership, no. (\%) } \\
\hline Heads, chiefs, chairs, and directors & $56(91.8)$ & $5(8.2)$ & $61(100)$ \\
\hline $\begin{array}{l}\text { Second in command: associate chiefs, vice } \\
\text { chairs, deputy directors }\end{array}$ & $7(63.6)$ & $4(36.36)$ & $11(100)$ \\
\hline Citations & USA & Canada & \\
\hline Assistant professors & $n=110$ & $n=29$ & $n=139$ \\
\hline Median & 103.5 & 53 & 96 \\
\hline Range & $0-4935$ & $2-4507$ & $0-4935$ \\
\hline Associate professors & $n=71$ & $n=23$ & $n=94$ \\
\hline Median & 292 & 376 & 301.5 \\
\hline Range & $0-15,039$ & $4-7871$ & $0-15,039$ \\
\hline Professors & $n=61$ & $n=19$ & $n=80$ \\
\hline Median & 2065 & 1081 & 1745 \\
\hline Range & $22-21,708$ & 0-9548 & $0-21,708$ \\
\hline \multicolumn{4}{|l|}{ Publications } \\
\hline Assistant professors & $n=128$ & $n=34$ & $n=162$ \\
\hline Median & 12 & 12.5 & 12 \\
\hline Range & $1-144$ & $2-245$ & $1-245$ \\
\hline Associate professors & $n=80$ & $n=24$ & $n=104$ \\
\hline Median & 23 & 28.5 & 23.5 \\
\hline Range & $2-349$ & $2-177$ & $2-349$ \\
\hline Professors & $n=70$ & $n=20$ & $n=90$ \\
\hline Median & 81.5 & 55 & 72 \\
\hline Range & $5-460$ & $3-285$ & $3-460$ \\
\hline
\end{tabular}

\section{Median H Index according to Academic Ranks and Gender}
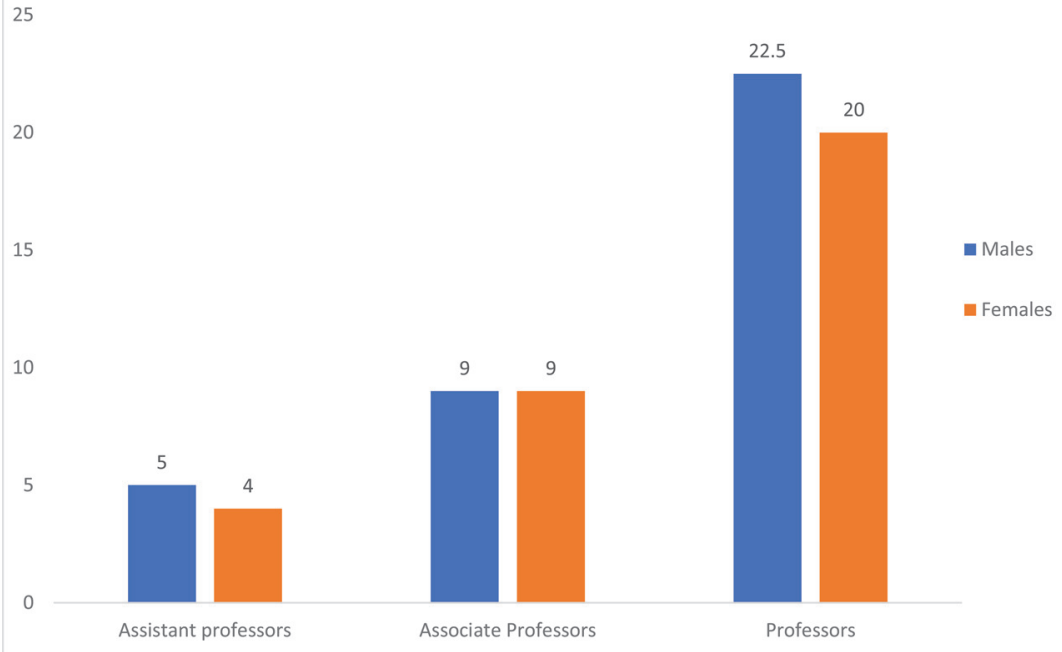

FIG 1. Distribution of median $\mathrm{H}$-index according to academic ranks and gender.

multicollinearity seen. Main effects were identified by using a stepwise selection strategy and were based on the $P$ value; we decided to either preserve a variable in the model or to drop it. As one example, years of research $(P=.30)$ was dropped from the model. The multivariable analysis supported the inclusion of gender, citations, publications, academic rank, and leadership rank in the preliminary model. The final step was to check for interaction effect. Interaction terms were created between each of the main effects in the model; 2 examples include significant interaction between gender and citations and between gender and publications. Academic rank, publications, and citations were not confounders for the H-index.

The final model:

$\mathrm{y}(\mathrm{x})=\beta_{0}+\beta_{1}$ (Gender) $+\beta_{2}$ (Publications) $+\beta_{3}$ (Citations) $+\beta_{41}$ (Academic Rank: Associate Professor) $+\beta_{42}$ (Academic Rank: Professor) $+\beta_{5}$ (Leadership Rank: Second in Command $)+\beta_{61}$ (Gender $\times$ Publications $)$ $+\beta_{62}$ (Gender $\times$ Citations)

Female faculty had odds of 0.84 compared with male faculty, also having a higher $\mathrm{H}$-index when adjusting for publications, citations, academic rank, leadership rank, and interaction between gender and publications and gender and citations. This prediction equation accounted for major variability in the model as adjusted with $R^{2}=0.92$; the $F$ test was 57.11 , and the $P$ value was $\leq$ .001 . The remaining variability in the model may have been explained by variables such as full-time versus part-time employment, years of employment, and contract versus tenure positions. Examining these additional variables was beyond the scope of our paper, as we used data that were publicly available.

\section{DISCUSSION}

Neuroradiology faculty members are predominantly men, similar to the genpublications, citations, years of active research, academic ranks, and leadership ranks. These variables were selected for inclusion into multivariable linear regression analyses. We checked for multicollinearity between independent variables, which were assessed by using a correlation coefficient. The Cramer V test was used for 1 nominal and 1 ordinal variable; the Spearman test was used for 1 continuous variable and 1 ordinal variable. A correlation of 0.8 was treated as the presence of multicollinearity. There was no der imbalance seen in diagnostic radiology and many other specialties in medicine as previously demonstrated. ${ }^{13-19}$ Women fill only $25 \%$ of assistant professor positions, $23 \%$ of associate professor positions, and $21 \%$ of professor positions among neuroradiology faculty members analyzed in our study. It may be argued that women only comprise $27 \%$ of radiology residents according to 2014 Association of American Medical Colleges data, and a continuation of that fraction through the rising ranks suggests 
Table 2: Association of academic hierarchy and leadership roles with gender of faculty

\begin{tabular}{|c|c|c|c|c|c|c|c|}
\hline \multicolumn{4}{|c|}{ Association of Gender with Academic Rank } & \multicolumn{4}{|c|}{ Association of Gender with Leadership Rank } \\
\hline Men, no. (\%) & Women, no. (\%) & $\chi^{2}$ & $P$ value & Men, no. (\%) & Women, no. (\%) & $\chi^{2}$ & $P$ value \\
\hline 341 (76.29) & 106 (23.71) & 0.46 & .79 & $63(87.5)$ & 9 (12.5) & 6.76 & .009 \\
\hline
\end{tabular}

that the $20 \%-25 \%$ range in faculty rankings may be appropriate. ${ }^{27}$ Gender disparity was highly significant for leadership positions $\left(\chi^{2}=6.76 ; P=.009\right.$ [Table 2] $)$.

The reasons for gender disparity in neuroradiology leadership positions are likely multifactorial and warrant examination. Previous studies exploring women in academic medicine have shown unique barriers faced by female physicians throughout their careers. ${ }^{28}$ For example, female physicians have been shown to have fewer available same-sex mentors, receive fewer research opportunities, and also encounter greater difficulty in obtaining funding from the National Institutes of Health. ${ }^{28}$ Some experts also believe that additional responsibilities such as child care and disproportionate home responsibilities outside of work are genderspecific barriers unique to women. ${ }^{28}$ Hofler et al ${ }^{29}$ examined these encumbrances and concluded that specialties that allow for more predictable work hours may lead to fewer gender disparities. Others refute these contentions and state that increasing numbers of women are choosing to make personal sacrifices at the expense of advancing their professional lives and careers. ${ }^{30}$

A recent study of women in leadership positions in emergency medicine residency programs by Cheng et $\mathrm{al}^{31}$ demonstrated that of 133 university emergency medicine programs in the US, 7.5\% have a female chair. Compared with other emergency medicine programs in the US overseen by male chairs, programs with female chairs had a higher percentage of female faculty (22\% versus $31 \%$ ). Studies have shown that having an identifiable mentor doubles a physician's chance of being promoted. ${ }^{32}$ Mentorship, leadership, and promotion are connected, leading to the contention that female physicians with guidance, role models, and mentors are more likely to be promoted in academic centers.

In terms of satisfaction in regards to mentorship, previous studies have shown that male physicians report higher satisfaction with the mentoring experience than their female counterparts (53\% versus $42.5 \%$ ). ${ }^{28}$ The lack of women in leadership positions within neuroradiology is a contributory cause for concern. Without active correction, this lack of female mentors will likely perpetuate the lack of women in academic leadership positions.

In exploring research productivity and citation counts, we assessed the $\mathrm{H}$-index of faculty members to identify the presence of discrepancies between men and women. The H-index is based on the most cited papers of the author, other publications, and the number of citations they have received from other authors. ${ }^{33}$ The $\mathrm{H}$-index is widely used to evaluate and compare scholarly efforts and is particularly helpful when assessing impact because it represents not only quantity, but also quality of publications as judged by citability. This information is often used to help with promotion decisions and the allocation of funding resources and is therefore meaningful and important where academic rank promotion potential and leadership promotion are concerned. ${ }^{33}$

We studied the $\mathrm{H}$-index for 360 of the total 465 faculty members, and we discovered that median $\mathrm{H}$-index was higher among male faculty compared with female faculty (17.5 versus 9 [Table
Table 3: Median $\mathrm{H}$-index according to gender

\begin{tabular}{|c|c|c|}
\hline H-Index & Men & Women \\
\hline \multicolumn{3}{|l|}{ Overall } \\
\hline Median & & \\
\hline Range & & \\
\hline$n=360$ & 281 & 79 \\
\hline Median & 17.5 & 9 \\
\hline Range & $1-76$ & $1-51$ \\
\hline
\end{tabular}

3]. As one measure of potential future academic success, previous studies in Academic Radiology have suggested that an $\mathrm{H}$-index of 10 may represent a reliable metric to determine the likelihood of receiving funding from the National Institutes of Health. ${ }^{34}$ In our analysis, male faculty members had more citations and publications than women in all academic ranks (Table 1). Upon applying the Kruskall-Wallis test, there was a significant gender-related difference between academic ranks and $\mathrm{H}$-index (Fig 1) across all academic ranks $\left(\chi^{2}=113.32 ; P \leq .0001\right)$. As noted, female faculty members had fewer total citations compared with men (Table 1).

The demonstrated difference between academic ranks and $\mathrm{H}$ index suggests the importance of research productivity. This finding also highlights concerns regarding barriers female physicians may face in academic faculty ranks. A recent study assessing radiology faculty demonstrated that men and women were similarly likely to be full professors; however, differences in promotion and research productivity were also present, suggesting that female radiologists may lack equal research opportunities. ${ }^{35}$ Our findings suggest that to minimize gender disparities in leadership positions, female physicians will benefit from increased availability of mentors and opportunities for research and funding.

\section{Limitations}

One of our study limitations recognizes that we collected our information regarding faculty members from publicly accessible academic department Web sites. It is possible that the information on these Web sites may not have been up to date. One additional limitation is that our methodology represents a snapshot in time. This is important because a female faculty member may have served in a leadership role several years prior, which would not be present on current data, yet would be important for reporting their involvement. We were also unable to determine the $\mathrm{H}$ index for 105 of the total 465 faculty members because of a lack of available information. In addition, we were not able to determine all sought statistics for each faculty member. For example, if we were able to secure career stage, age, and length of time the person has been in his or her current role, that would have allowed us to perform a more detailed analysis. Another variable that we were unable to reliably calculate but could help explain gender disparity in leadership roles is the shortened career duration of women in academic medicine, in many instances because of their choosing to recuse themselves from full-time academic positions as a result of shouldering a disproportionate share of home and child- 
care responsibilities. Diamond et $\mathrm{al}^{36}$ determined that women in their cohort had overall lower research productivity than men, but when they corrected for career duration, this difference was insignificant. Another consideration is that often authors publish under different names. This is important in several scenarios such as when a person, regardless of gender or sexual orientation, changes their name after marriage or divorce, takes their spouse's surname, or creates a hyphenated name; or in the case of a transgender person who may change his or her name. When these name changes are taken into consideration, it shows that the number of publications and $\mathrm{H}$-index for female faculty may be erroneously underestimated. The inclusion or exclusion of middle initials can also contribute to miscalculations of attributable academic productivity.

\section{CONCLUSIONS}

Gender disparities exist in neuroradiology, especially where leadership positions are concerned. The gender discrepancies that are observed in this traditionally male-dominated field can be used to better inform the medical community regarding issues related to gender imbalances in academic medicine. We recommend that early mentorship, with ensuing increased directed opportunities and groomed career development of female faculty, could play a key role in helping diversify academic medicine. Many radiology societies have recognized the importance of mentorship and have created programs to help empower and promote women, including the American Association for Women Radiologists and the Women in Radiology branch of the Society of Interventional Radiology. In 2012, the American Society of Neuroradiology, American College of Radiology, and the American Association for Women Radiologists jointly funded the Women in Neuroradiology Leadership Award to support leadership training for female neuroradiologists. Ongoing studies are needed to examine trends over time relating and connecting factors such as mentorship, ranking promotion, academic productivity, and methods to help eliminate the underlying causes of the gender gap. We hope that our work will catalyze and substantiate further directed initiatives that will help female physicians achieve and occupy both senior faculty and leadership positions and help blaze pathways to durable success in leadership careers.

Disclosures: Alexander Norbash—UNRELATED: Board Membership: Boston Imaging Core Laboratories, Comments: co-founder; Consultancy: Stryker, IBM, GE Healthcare, Comments: scientific consultant. Savvas Nicolaou-UNRELATED: Consultancy: Siemens Healthcare, Comments: scientific consultant*. *Money paid to the institution.

\section{REFERENCES}

1. Association of American Medical Colleges. Women in Academic Medicine. https://www.aamc.org/members/gwims/statistics/. Accessed April 2, 2017

2. Nonnemaker L. Women physicians in academic medicine: new insights from cohort studies. N Engl J Med 2000;342:399-405 CrossRef Medline

3. Magrane D. The changing representation of men and women in academic medicine. Association of American Medical Colleges: Analysis in Brief 2005;5:1-2

4. Carr PL, Gunn CM, Kaplan SA, et al. Inadequate progress for women in academic medicine: findings from the National Fac- ulty Study. J Women's Health (Larchmt) 2015;24:190-99 CrossRef Medline

5. Bickel J. Women in academic medicine. J Am Med Womens Assoc (1972) 2000;55:10-12, 19 Medline

6. Sidhu R, Rajashekhar P, Lavin VL, et al. The gender imbalance in academic medicine: a study of female authorship in the United Kingdom. J R Soc Med 2009;102:337-42 CrossRef Medline

7. Reck SJ, Stratman EJ, Vogel C, et al. Assessment of residents' loss of interest in academic careers and identification of correctable factors. Arch Dermatol 2006;142:855-58 CrossRef Medline

8. Bickel J, Brown AJ. Generation X: implications for faculty recruitment and development in academic health centers. Acad Med 2005; 80:205-10 CrossRef Medline

9. Alexander H, Lang J. The long-term retention and attrition of U.S. medical school faculty. Association of American Medical Colleges: Analysis in Brief 2008;8:1-3

10. Forman HP, Larson DB, Kaye AD, et al. Masters of radiology panel discussion: women in radiology-how can we encourage more women to join the field and become leaders? AJR Am J Roentgenol 2012;198:145-49 CrossRef Medline

11. Anzai Y, Meltzer CC, DeStigter KK, et al. Entrepreneurial women in radiology: role models of success. J Am Coll Radiol 2016;13:1378-82 CrossRef Medline

12. Levinson W, Kaufman K, Clark B, et al. Mentors and role models for women in academic medicine. West J Med 1991;154:423-26 Medline

13. Pashkova AA, Svider PF, Chang CY, et al. Gender disparity among US anaesthesiologists: are women underrepresented in academic ranks and scholarly productivity? Acta Anaesthesiol Scand 2013;57: 1058-64 CrossRef Medline

14. Singh A, Burke CA, Larive B, et al. Do gender disparities persist in gastroenterology after 10 years of practice? Am J Gastroenterol 2008; 103:1589-95 CrossRef Medline

15. Lopez SA, Svider PF, Misra P, et al. Gender differences in promotion and scholarly impact: an analysis of 1460 academic ophthalmologists. J Surg Educ 2014;71:851-59 CrossRef Medline

16. Eloy JA, Svider PF, Kovalerchik O, et al. Gender differences in successful NIH grant funding in otolaryngology. Otolaryngol Head Neck Surg 2013;149:77-83 CrossRef Medline

17. Paik AM, Mady LJ, Villanueva NL, et al. Research productivity and gender disparities: a look at academic plastic surgery. J Surg Educ 2014;71:593-600 CrossRef Medline

18. Mueller CM, Gaudilliere DK, Kin C, et al. Gender disparities in scholarly productivity of US academic surgeons. J Surg Res 2016; 203:28-33 CrossRef Medline

19. Wyrzykowski AD, Han E, Pettitt BJ, et al. A profile of female academic surgeons: training, credentials, and academic success. Am Surg 2006;72:1153-57; discussion 1158-59 Medline

20. Baker SR, Barry M, Chaudhry $H$, et al. Women as radiologists: are there barriers to entry and advancement? J Am Coll Radiol 2006;3: 131-34 CrossRef Medline

21. Zener R, Lee SY, Visscher KL, et al. Women in radiology: exploring the gender disparity. J Am Coll Radiol 2016;13:344-50.e1 CrossRef Medline

22. Vydareny KH, Waldrop SM, Jackson VP, et al. Career advancement of men and women in academic radiology: is the playing field level? Acad Radiol 2000;7:493-501 CrossRef Medline

23. Bluth EI, Bansal S, Macura KJ, et al. Gender and the radiology workforce: results of the 2014 ACR workforce survey. J Am Coll Radiol 2015;12:155-57 CrossRef Medline

24. Fielding JR, Major NM, Mullan BF, et al. Choosing a specialty in medicine: female medical students and radiology. AJR Am J Roentgenol 2007;188:897-900 CrossRef Medline

25. Roubidoux MA, Packer MM, et al. Female medical students' interest in radiology careers. J Am Coll Radiol 2009;6:246-53 CrossRef Medline

26. Potterton VK, Ruan S, Sunshine JH, et al. Why don't female medical students choose diagnostic radiology? A review of the current literature. J Am Coll Radiol 2004;1:583-90 CrossRef Medline

27. AAMC 2014 Physician Specialty Databook. https://www.aamc.org/ 
data/workforce/reports/439208/specialtydataandreports.html. Accessed April 1, 2017

28. Kaplan SH, Sullivan LM, Dukes KA, et al. Sex differences in academic advancement. Results of a national study of pediatricians. $N$ Engl J Med 1996;335:1282-89 CrossRef Medline

29. Hofler L, Hacker M, Dodge L, et al. Comparison of women in department leadership in obstetrics and gynecology with those in other specialties. Obstet Gynecol 2016;127:442-47 CrossRef Medline

30. Burke CA, Sastri SV, Jacobsen G, et al. Gender disparity in the practice of gastroenterology: the first 5 years of a career. Am J Gastroenterol 2005;100:259-64 CrossRef Medline

31. Cheng D, Promes S, Clem K, et al. Chairperson and faculty gender in academic emergency medicine departments. Acad Emerg Med 2006; 13:904-06 CrossRef Medline
32. Beasley BW, Simon SD, Wright SM. A time to be promoted. The prospective study of promotion in academia. J Gen Intern Med 2006; 21:123-29 CrossRef Medline

33. Hirsch JE. An index to quantify an individual's scientific research output. Proc Natl Acad Sci U S A 2005;102:16569-72 CrossRef Medline

34. Rezek I, McDonald RJ, Kallmes DF. Is the $\mathbf{H}$-index predictive of greater NIH funding success among academic radiologists? Acad Radiol 2011;18:1337-40 CrossRef Medline

35. Kapoor N, Blumenthal DM, Smith SE. Gender differences in academic rank of radiologists in U.S. medical schools. Radiology 2017; 283:140-47 CrossRef Medline

36. Diamond SJ, Thomas CR Jr, Desai S, et al. Gender differences in publication productivity, academic rank, and career duration among U.S. academic gastroenterology faculty. Acad Med 2016;91: 1158-63 CrossRef Medline 